\title{
HOSPITALS OF THE FUTURE
}

BY

LORD TAYLOR, M.D., F.R.C.P.

Medical Director, Harlow Industrial Health Service; Member, Harlow Development Corporation

Inevitably and always, most hospitals of the future will be hospitals of the past. It follows that it is more important to know how to improve existing hospitals than build new ones. Improvement is less glamorous than new building; there are seldom foundation-stones to lay and plaques to unveil ; and there is less scope for political self-congratulation. Yet in the total scheme of things in Britain, in planning and in spending, new building ought to come a long way behind the job of improving what we already have. Recently I visited a general pathology laboratory in an E.M.S. hut. It had cost $£ 17,000$ to make the necessary adaptations and $£ 3,000$ to equip. It was a superlative job, perfectly fitted for its work. Had it been tackled as a new block, the regional board would have been lucky to escape with a bill of under $£ 100,000$. In thirty years both laboratories will be obsolete. Yet it is usually harder to get money for modest capital reconstruction than for major grandiose new building.

Reconstruction may be cheap, but it is not easy. It requires as much intelligence and thought, planning, and good taste as new building. It often requires even more administrative battling. The greater is the credit due to the hundreds of hospital management committees, doctors, matrons, lay administrators, and works departments who have been quietly working miracles in the past ten years, often out of maintenance budgets. When reconstruction of any department is contemplated the following rules may be helpful:

1. See what others have done by way of reconstruction and new building, especially where the burden of work is similar. Make notes of design, finishes, equipment, and furnishing. Ask about snags and successes in both building and operation.

2. Draw up a detailed description on paper of what you think you want. Be prepared to rewrite this three or four times if necessary; your original proposals will certainly be capable of improvement. Such a description must include a detailed projection of the probable burden of work for the next ten years. You will find no one really knows what this is likely to be even in terms of population. Get the help of a statistician if you can. Study your own trends and the trends of others.

3. Remember always that the patient is the centre of the picture. The patients' entrance must be the main entrance, and the patients' waiting and examination rooms must be such as one would wish for one's own family. Keep the patients' rooms small and intimate.

4. Study heating, lighting, and ventilation. Too much of any of these is as bad as too little.

5. Attend carefully to detail. Ugly finishes, decoration, and furniture can ruin the best of designs.

6. Avoid tubular metal furniture. Nothing gives a place a shoddier look more quickly.

7. Remember that the aim is a cheerful, friendly atmosphere for patients and staff. Avoid anything conventionally institutional.

8. Fight patiently and politely until you get what you want. If what you want is right, you will get it in the end. You will certainly tire, but this is only an indication for further effort. The price of success is persistent persistence.

When, however, all this is done, or indeed when nothing is done, achievement in a hospital or a depart- ment depends not on buildings but on human beings. Group morale stems from the top, and those in charge have not only to do their job well but to encourage others. Every group has its psychopaths and we have got to make the best of them. Next to technical inefficiency, rudeness to patients is the greatest sin of all. Moreover, it is infectious and can spread downwards. Fortunately the same applies to courtesy and politeness.

\section{New Building}

Most of us have never built a hospital; but in the next twenty years many of us will be playing some part in hospital building. So we had better learn our job. My only claims to write on this are: an interest in social medicine, and an experience in helping to build a town.

A hospital is not a "factory" for health as some people think ; factories shape inanimate objects. It is much nearer to a school, and nearer still to a "little town." In one sense it is a temporary home for those who are sick, in which all their human needs must be met. In another sense it is an institute for scientific research, for each patient presents a research problem of diagnosis and a practical problem of therapy.

Our town now houses 50,000 people. So far it has cost $136 \mathrm{~m}$. This includes homes, factories, shops, public houses, community centres, health centres, roads, water supply, drains, a sewage works, and much else. The capital cost has been about $£ 700$ per person, and we are now making a profit. Remember this figure when we come to look at hospital costs.

Before a brick was laid, or even a house designed, in our town a team of experts-not a committee of amateurs-spent two years on research and planning. Engineers and geologists, commercial and traffic experts, statisticians and sociologists, architects and townplanners worked together to draw up a master-plan. Then the amateurs approved it, with little or no modification. So the success or failure of our town was determined before a single house-plan was drawn. I suspect it is just the same with a hospital.

\section{Hospital Costs}

Look for a moment at a modern hospital. The University Hospital of Wales is to have 650 beds. It will cost $£ 7 \mathrm{~m}$. to build and another $£ 1 \mathrm{~m}$. to furnish and equip, or more than $£ 10,000$ a bed (Fig. 1). Admittedly this includes a medical school. But $£ 8,000$ a bed seems to be a common cost to-day. Is it really right to spend ten times as much on a hospital bed as on a home, workplace, shops, and all the rest for a person out of hospital?

Of course there are many qualifications about these figures. Each hospital bed will be occupied by somewhere between 9 and 18 people in the course of a year. 650 sick people in hospital will need nearly as many well people to look after them. Then there are the outpatient and casualty attendances. But when all this is allowed for, we are paying the bill, and I suspect we are paying too much. Why do things go wrong? 
When a hospital is planned to-day everyone concerned wants the optimum maximum, and no one is paying personally. Heaven forbid that the ratepayers should watch costs, as in the old days; the results of that were disastrous. The Ministry of Health is the official watchdog of the public purse, and every capital scheme costing more than $£ 30,000$ must be submitted to the Ministry at four different stages. I think this is three times too many and that the one essential step is left out. The Ministry should tell the hospital authorities how much they can spend at the start-and not a penny more should they give. There is nothing like having to build to a price to achieve efficiency, and to control the megalomanic tendencies which we all display when, as architects or doctors, committee members or administrators, we get our hands on other people's money.

Success in hospital building depends on putting our emotions in cold storage. We have to study hospital building as a science.

\section{Science of Hospital Planning}

Hospitals are built as a response to human need. Their pattern must reflect the nature of the need they exist to meet. As the need changes so they must change. Parts will grow and other parts atrophy. Since hospitals are human societies, atrophy is painful and apt to be resisted. The object of medical science, taking a very long view, is to do away with hospitals. But so long as human life ends in death they will have work to do.

To-day medical science is working overtime. The chemotherapists, virologists, and the public health services are changing the internal pattern of our hospitals faster than ever before. They have already reduced the need for beds for the acute specific fevers, tuberculosis, poliomyelitis, venereal disease, and general children's diseases. The number of beds occupied by tuberculous patients has fallen in ten years from 26,115 to 14,500 though in the first four years of the last decade the figure went up. In ten years waiting-lists have dropped from 11,000 to just under 400 ; notifications from 52,000 to 29,000 ; and deaths from 20,000 to about $4,000 .^{1}$ This is a triumph for therapeutic and social medicine, with, however, profound implications for the hospitals.

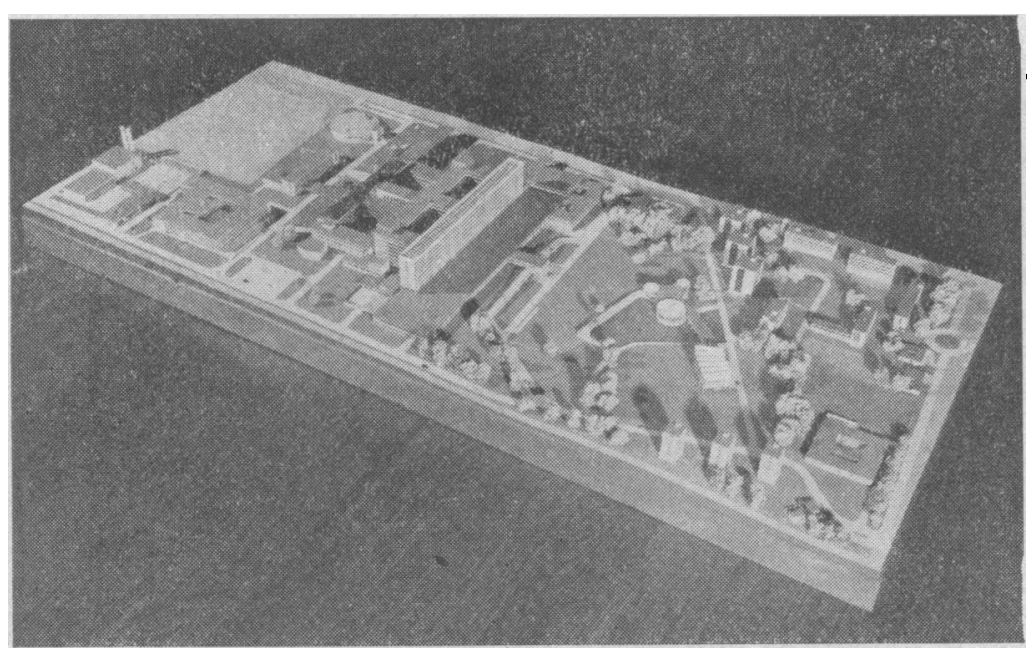

Fio. 1.-The winning design in the competition for the Cardiff Teaching Hospital and Medical Centre (Architects: $\mathbf{S}$. W. Milburn and Partners.) Note the huge expanse of low building in front of the main block; this will require overhead or artificial light. Note also the deep shadow in the quadrangles behind the main block; contrast this with the free-falling shadows from the tower blocks in the lower right foreground. Crown copyright.
Note the pattern followed: new methods of treatment; an increase in beds to make them generally available; then victory on such a scale that in six years the number of beds needed can be nearly halved. I think we are going to see the same pattern followed in the next ten years in psychiatry. As we get our modern small psychiatric blocks attached to general hospitals, and develop our home psychiatric services, we shall be able to close and bulldoze more than half the old mental hospitals. Dr. T. P. Rees was right when he said they produce more psychoses than they cure.

A new response to human need may mean a longterm increase in the number of hospital beds. Admissions for thoracic surgery are up $130 \%$. But even now such cases occupy under 2,000 beds. It looks as though the decreases will be more spectacular than the increases.

We may conclude thus: because of the speed of advance of scientific medicine, changes in the nature of the work done by hospitals are likely to be more rapid than ever before. Medical success may well produce more redundancy of beds and staff, which is always painful for those concerned. This means that buildings -and specialists-must retain flexibility. The freezing of the present picture in monumental edifices could be disastrous.

At the same time our hospital inheritance is dilapidated and dismal. Upgrading and replacing, even at a lower level of need, will take all we can afford in money, time, and brain-power for the next thirty years. All the more reason why, if we are to put right what is wrong as quickly as we can, we should not overbuild or overprovide. If we could halve the cost of hospital beds without loss of essential quality, we could do twice as much in any one year, and the whole job in half the time. This is the challenge to the hospital planners of the future.

\section{A Hospital Master-plan}

Whether it is a case of new building or adaptation, the planning of a hospital ought to begin with a master-plan. This is a book of words and not a drawing. If the mașter-plan is right, there will be little excuse for the architect to go wrong. The making of a masterplan is a job for experts. It might take from six months to two years to prepare, and cost between $£ 10,000$ and $£ 40,000$. In the long run it may save ten or twenty times these amounts. The planners must be experts in statistics, social medicine, work-study, and functional planning. They must have access to all the users, and question them and watch them at their work. They must have a chief, a planner-co-ordinator, but they must serve no committee until their work is in final draft form. Sketchy master-plans, prepared by doctors without statistical training, are beginning to be seen nowadays. But these are first steps only, and inevitably they can be very misleading.

This is what the planners will have to do:

1. Define and analyse by age and sex the population the hospital is intended to serve, with projections of probable future populations similarly analysed.

2. Analyse the morbidity of this population, present and future, and its social setting. 
3. Estimate the facilities needed to deal with this morbidity in terms of beds and of out-patient, casualty, and other special departments.

4. Study each department in detail to find out the work actually done, and the minimum accommodation needed to do this work efficiently.

5. Relate the work of each department in terms of movement of patients and staff.

6. Examine the communications for patients, relatives, and staff within the area served in relation to ideal and possible locations.

At the end there will emerge a word-picture of the future hospital that will have real meaning, ready for the potential users-doctors, nurses, administrators, and the rest-to criticize, or even approve without criticism. Only when their criticisms have been examined by the planners, and incorporated where appropriate, is the project approaching readiness for the architect to look at and start his sketch plans. He will have before him a task within his capacity, where his own specialist skills can properly come into play.

Some of the parts of the "Master-Plan" will now be looked at in greater detail.

\section{Population to be Served}

The population to be served is easily measured where a community is physically isolated. It is less clear where there is any substantial overlap in catchment areas at the margins. Since there is, and ought to be, freedom of choice for both doctors and patients, movement both ways over any catchment area margin is inevitable and right. One may assume, unless there are special units serving wider areas or other unusual circumstances, that this movement will cancel itself out.
Future population will depend on fertility, the deathrate, and migration in and out. Any competent social scientist can work this out, but his estimate will inevitably be subject to regular revision as circumstances alter away from his lines of prediction.

Age distribution of the population must also be determined and predicted for the future. In places undergoing social and economic decay there is a steady ageing of the population. Young folk migrate away before or after marriage. Fewer children are born. So the population gets an increasing geriatric skew. This will reflect itself not only in conventional geriatric needs but also in needs for extra beds for old people in general medical, general surgical, and traumatic and orthopaedic wards, and fewer beds for children and young adults and for midwifery.

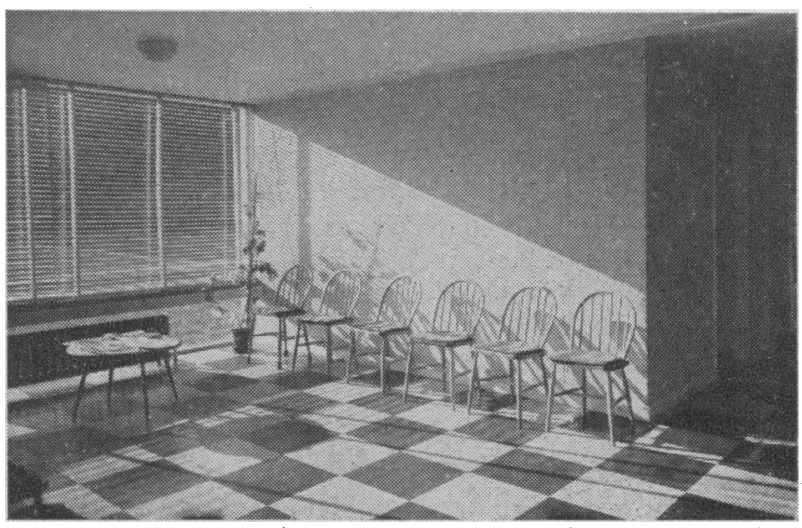

FIG. 3.-Patients' waiting-space at Corby. Simple, homely but attractive furnishings and furniture. (Photographers: de Burgh Galwey.)

\section{PHYSIOTHERAPY}

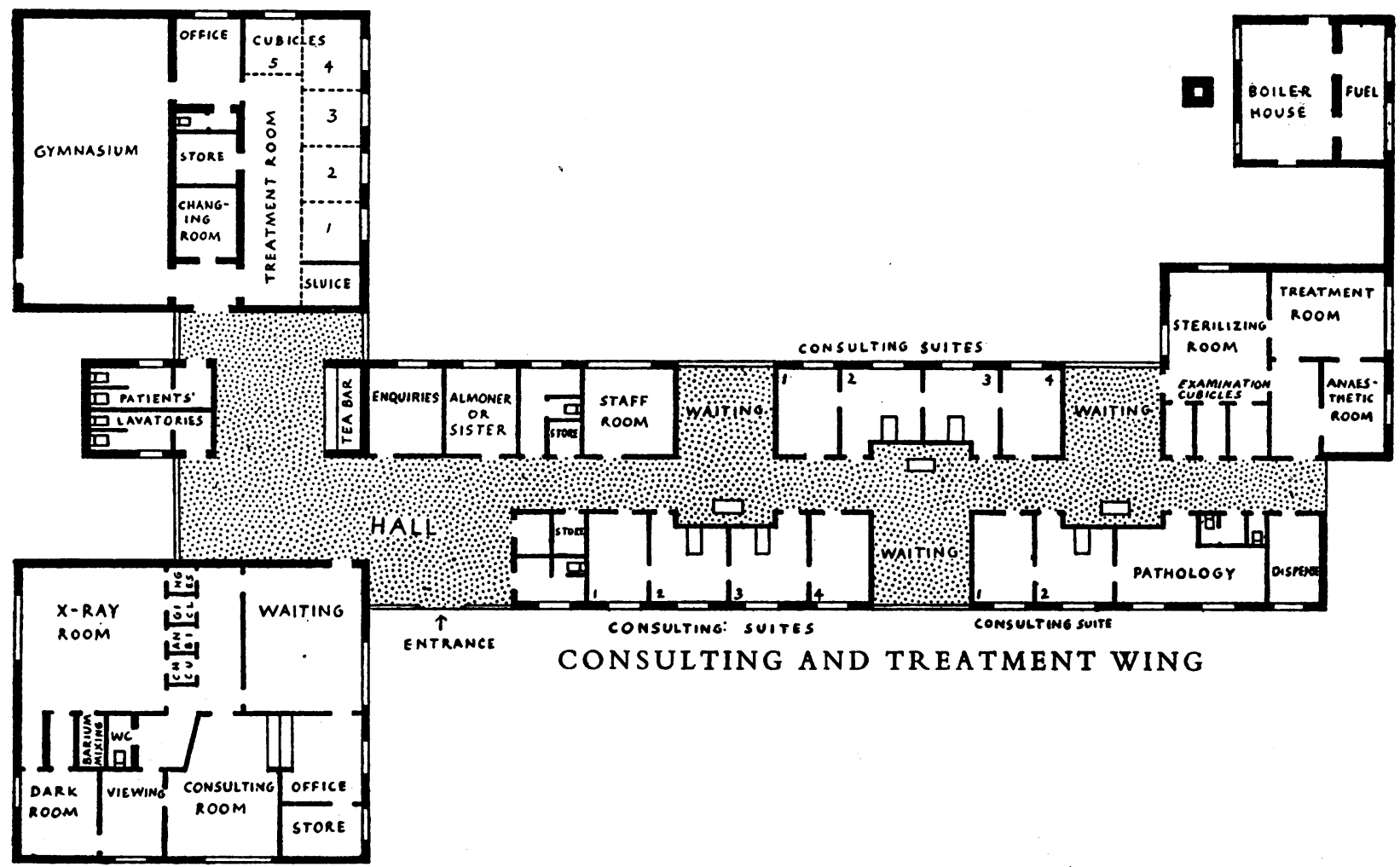

X-RAY \& CHEST CLINIC

Fig. 2.-Plan of the Nuffield Diagnostic Centre at Corby. A simple and inexpensive but highly efficient out-patient department. (Architect: Richard Llewelyn Davies, F.R.I.B.A.) Plan by courtesy of the Nuffield Provincial Hospitals Trust. 
At the other extreme are the new or developing communities. Here the population skew is towards paediatrics and obstetrics. Thanks to improved nutrition and antibiotics, the needs for beds for sick children have been lessening throughout the country. Once infancy is passed, the needs of a community for hospital beds remain at a comparatively low level, apart from obstetric need, until the fourth decade.

It follows that a new or developing community is likely to need a comparatively smaller number of general beds for some years, but it will not retain this indefinitely. After, say, twenty years it will come to approximate to the general picture for the country as a whole. From then on, unless it absorbs its own children, it will have a

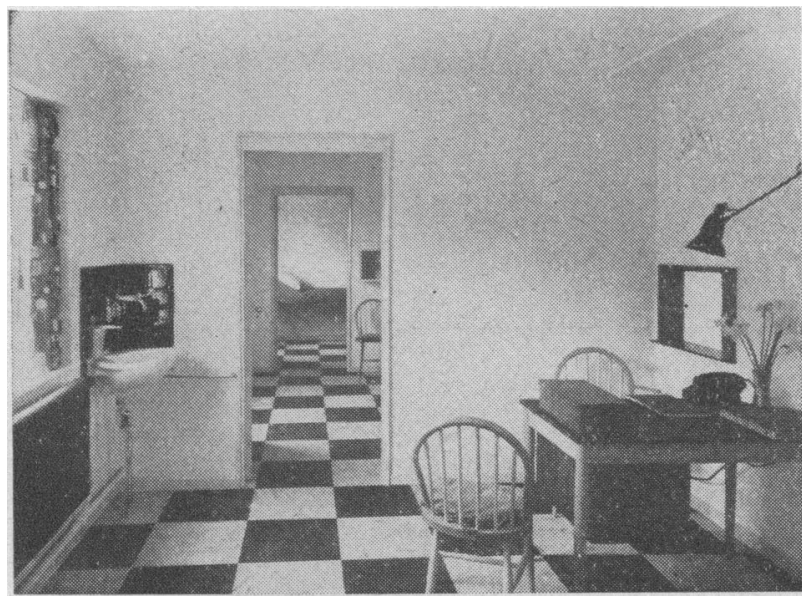

Fio. 4.-Consulting suite at Corby. Again, simplicity on a human scale. (Photographers : Peter Pitt.)

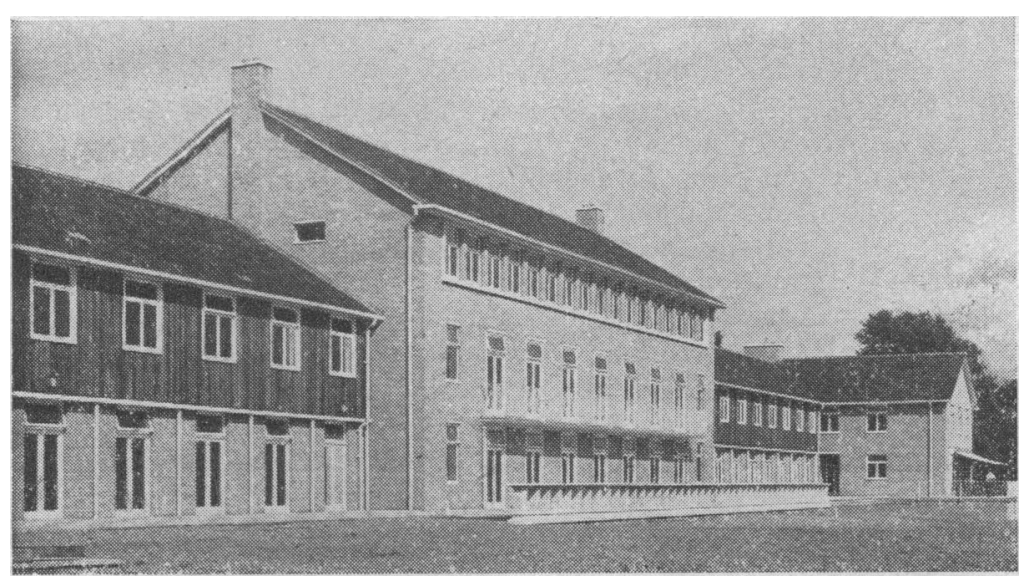

Fro. 5.-Halliwick Hospital for acute psychiatric cases, New Southgate H.M.C. 137 beds; provisional cost $£ 260,000$. (Architect: F. A. C. Maunder, F.R.I.B.A.) greater than average proportion of old people, and a consequent geriatric morbidity skew.

All this can be expressed with mathematical precision, preferably also in diagrammatic form as histograms or population pyramids.

Current thinking suggests that the optimum population for a single general hospital is about 150,000 . This figure is arrived at by calculating backwards from the present conception of optimum hospital size of 400-600 beds. This figure has been reached by rather imprecise socio-medical studies of hospitals. Swedish experience suggests that a hospital which is too big becomes socially incoherent and economically inefficient, while it is generally agreed that a hospital which is too small does not allow for the amount of specialization necessary for medical efficiency.

But within these margins much greater precision is needed. If 100 more beds than are actually required are provided, the extra bill will be nearly three-quarters of a million pounds. Moreover, the right figure for different areas will vary widely, depending on morbidity and local social conditions.

\section{Morbidity, Social Setting, and Hospital Need}

The importance of differential morbidity was brought home to me when carrying out the Nuffield survey of Good General Practice. ${ }^{2}$ The infant mortality in urban areas visited varied from 57 per 1,000 live births at one extreme to 16 per 1,000 live births at the other. Doctors' services per patient at risk per year varied from 7.8 in parts of South Wales to 3.8 in southern England. This variation in morbidity extended not only to the conventional social diseases, such as tuberculosis and rheumatic carditis, but also to many organic conditions, the cause of which is still unknown. An example is the variation in the incidence of pernicious anaemia revealed by the recent survey of the College of General Practitioners." Another striking example, with profound hospital implications, is chronic bronchitis and right-sided cardiac failure." Again, mothers in an area of former economic depression carry with them a legacy of juvenile malnutrition, with the result that obstetric difficulties of all kinds are more common.

The other extra-hospital variable is the degree to which the home care of illhealth and home midwifery are practical and desirable. If housing conditions are

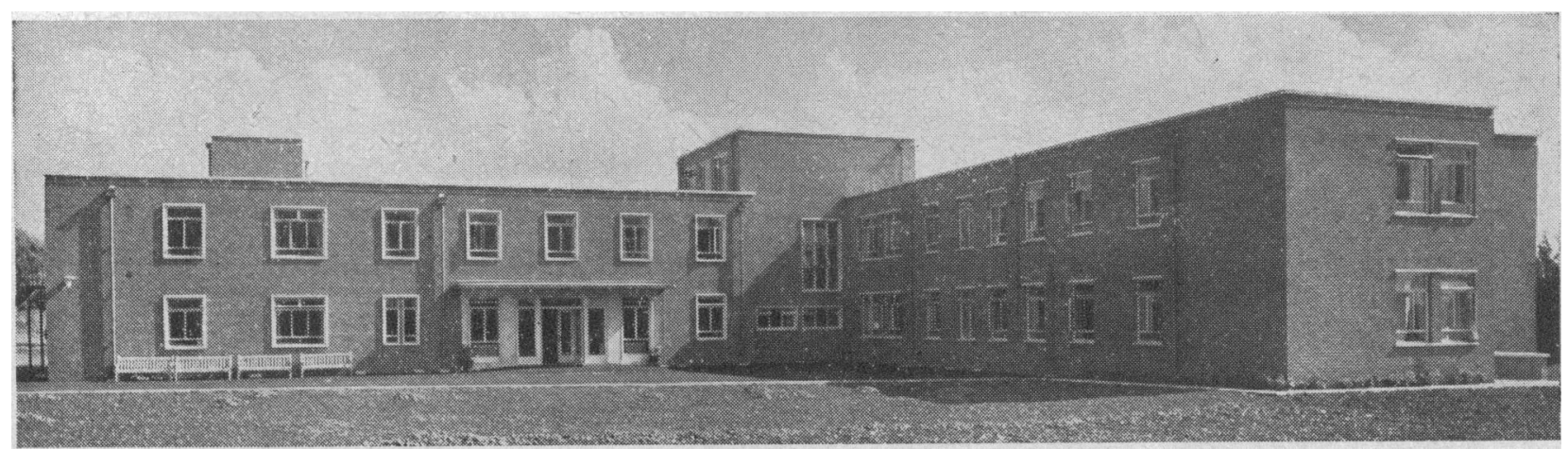

Fro. 6.-New maternity unit at Exeter City Hospital. (Architect: K. W. F. Harris, F.R.I.B.A.) 
good, home delivery and the efficient home care of much chronic sickness and psychiatric ill-health are possible and often desirable, provided there are proper home-help and home-nursing services. To provide these is far less expensive to society than to provide institutional beds. There is much evidence to show that most mothers prefer to have most of their babies at home. The Cranbrook Report recommendation of $70 \%$ hospital confinements is, in my view, unrelated to reality.

The synthetic build-up of the picture of hospital need may come as a shock to those doctors who are convinced that their departments should be greatly enlarged. It may also show that certain voices in the wilderness on the hospital staff-for example, the orthopaedic surgeons, the gynaecologists, and the psychiatrists-have far greater needs for beds than their general colleagues. Yet even here careful clinical analysis may show a tendency towards over-zealous hospitalization.

\section{Hospital Facilities Needed}

The check on the synthetic picture is provided by the examination of the actual use of existing hospital beds and the size of existing waiting-lists. For information about this we are largely indebted to the Nuffield Provincial Hospitals Trust. 5 o 7

The key figures arrived at so far by the Nuffield Trust investigators are summarized in Table I (further studies are in progress).

TABLB I.-Number of Beds for Acute Cases Needed Per 100,000 Population

\begin{tabular}{|c|c|c|c|c|}
\hline & Northampton & Norwich & Reading & Barrow \\
\hline 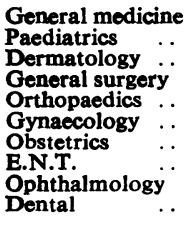 & $\begin{array}{c}\left.\begin{array}{c}27.4 \\
13.5 \\
2.1\end{array}\right\} 43 \\
68.9 \\
21.1 \\
26.9 \\
11.7 \\
7.2 \\
\text { Incl. in } \\
\text { general surgery }\end{array}$ & $\begin{array}{c}43 \cdot 4 \\
68.9 \\
30 \cdot 5 \\
10 \cdot 7 \\
20.4 \\
12 \cdot 2 \\
5.9 \\
\text { Incl. in } \\
\text { E.N.T. }\end{array}$ & $\left.\begin{array}{l}48 \\
12 \\
756\end{array}\right\} 60$ & $\begin{array}{r}57 \cdot 3 \\
11 \cdot 0 \\
5 \cdot 5 \\
67 \cdot 5 \\
24 \cdot 4 \\
30 \\
35.5 \\
14 \cdot 3 \\
9 \cdot 9 \\
0 \cdot 6\end{array}$ \\
\hline Total & $\begin{array}{c}\mathbf{1 7 8 \cdot 8} \\
\text { (excluding } \\
\text { orthopaedics) }\end{array}$ & 192.0 & $200 \cdot 3$ & 256.0 \\
\hline
\end{tabular}

There are a number of "ifs" and "buts" about this table which are thoroughly explored in the appropriate Nuffield Reports. However, two conclusions can be firmly drawn. First, the estimates made in the early

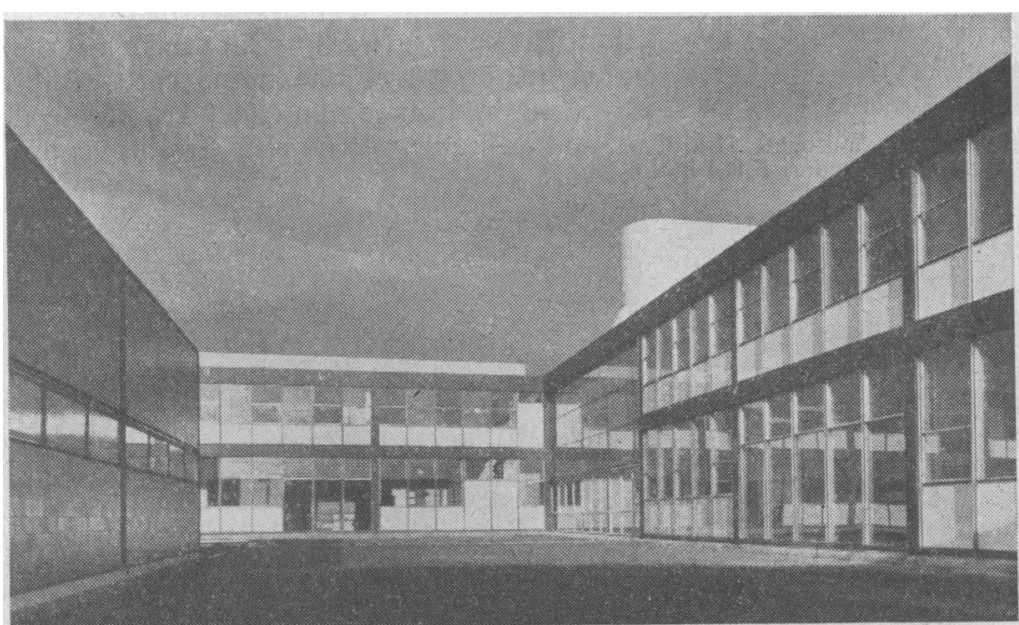

Fro. 7.-Princess Margaret Hospital, Swindon. Too much glass: (Architects : Powell and Moya, F.F.R.I.B.A., in association with R. Llewelyn Davies, F.R.I.B.A. and W. J. Jobsun, F.R.I.B.A., regional architect.) Reproduced by permission of the Architectural Review. days of the National Health Service of 500-700 beds for acute cases per 100,000 population were at least $100 \%$ too high. Secondly, local differences in morbidity and social setting may account for up to a quarter of the total number of beds needed.

A similar type of analysis may be made of out-patient consultations. Table II presents a composite picture, based primarily on the Northampton results, except where these are atypical.

If we assume that there are 300 working days a year, the average daily attendances on the above figures

TABLe II.-Out-patient Attendances Per 100,000 at Risk Per Annum

\begin{tabular}{|c|c|c|c|c|}
\hline & & $\begin{array}{l}\text { New } \\
\text { Cases }\end{array}$ & $\begin{array}{l}\text { Old } \\
\text { Cases }\end{array}$ & $\begin{array}{c}\text { Total } \\
\text { Attendances }\end{array}$ \\
\hline \multirow[t]{2}{*}{$\begin{array}{ll}\text { General medicine } \\
\text { Paediatrics } & \ldots \\
\text { Dermatology } & \ldots \\
\text { General surgery } & \ldots \\
\text { Gynaecology } & \ldots \\
\text { Obstetrics . . } & \ldots \\
\text { Orthopaedics } & \ldots \\
\text { Fracture clinic } & \ldots \\
\text { Ophthalmology } & \ldots \\
\text { Ear, nose, and throat } \\
\text { Dentistry . . } & . . \\
\text { Psychiatry } & \ldots \\
\text { Physical medicine }\end{array}$} & $\begin{array}{l}\ldots \\
\ldots \\
\ldots \\
\ldots \\
\ldots \\
\cdots \\
\cdots \\
\cdots \\
\cdots\end{array}$ & $\begin{array}{r}875 \\
185 \\
424 \\
1,935 \\
605 \\
680 \\
1,308 \\
314 \\
740 \\
1,430 \\
40 \\
185 \\
300\end{array}$ & $\begin{array}{r}3,500 \\
555 \\
1,272 \\
3,870 \\
907 \\
4,760 \\
3,620 \\
1,570 \\
2,960 \\
2,145 \\
30 \\
925 \\
1,500\end{array}$ & $\begin{array}{l}4,375 \\
740 \\
1,696 \\
5,805 \\
1,512 \\
5,440 \\
4,928 \\
1,884 \\
3,700 \\
3,575 \\
70 \\
1,110 \\
1,800\end{array}$ \\
\hline & & 9,021 & 27,614 & 36,635 \\
\hline
\end{tabular}

would be 122 patients per day, or 61 per half-day session. This is a smaller case-load than that dealt with in many three-member general practices in a group surgery. An ideal group-practice surgery for three doctors will cost $£ 10,000$. Yet a new out-patient department for 61 patients per half-day may cost $£ 200,000$. Clearly, the out-patient department must cost more. But unless major facilities for in-patients are also included, such a discrepancy would seem to require explanation.

The construction of tables of this type, and their extrapolation into half-days or other units of work, is a vital step in any hospital plan. It will soon become apparent that, if rooms are not to stand idle for large parts of each week, different departments must use the same rooms on different half-days-as indeed they have usually done in the past.

At a certain point, case-loads and work-units must begin to turn into rooms and work-spaces. All this has been explored in some detail by the Nuffield Provincial Hospitals Trust and the Division for Architectural Studies of the Nuffield Foundation. $^{5}$ The principles of the ideal small out-patient department have been given practical expression by the Trust at Corby. The quality is higher, and the cost is perhaps a quarter of that for conventional out-patient buildings (Figs. 2, 3, and 4).

It is beginning to be realized that it is a mistake to think of hospital beds as a uniform entity. I first grasped this when I learnt it was possible to build an ideal modern psychiatric unit of 137 beds for under $£ 300,000$ (Fig. 5). I then found that this also applied to a first-class maternity block. The excellent new maternity block at Exeter cost $£ 3,800$ per bed, or $£ 4,500$ per bed if the midwives' home was included (Fig. 6). Professor McKeown ${ }^{8}$ has found that 
only half the patients in hospital need the elaborate and full ward facilities. It is only for these beds that high-priced buildings are justified. Convalescent and psychiatric beds can be largely " self-running," inasmuch as most of the patients can play a substantial part in the routine work of the ward. Psychiatric and some geriatric patients need supervision and training rather than conventional nursing. Again, there is no need for lavish technical equipment for beds for the chronic sick; the nearer the provision can approximate to that of the patient's home the better; the idea may well be a series of small bed-sitting rooms with some open ward-space and a day-room. To provide expensive beds because it is architecturally convenient to have a standard ward design is manifest folly.

I must confess to seeing no future for generalpractitioner beds, save in very remote areas. That is not to say that some G.P.s with special experience should not have a proper place in hospital. But if general practice is to mean full specialization in extra-hospital medicine, in the home, the surgery, the clinic, the school,

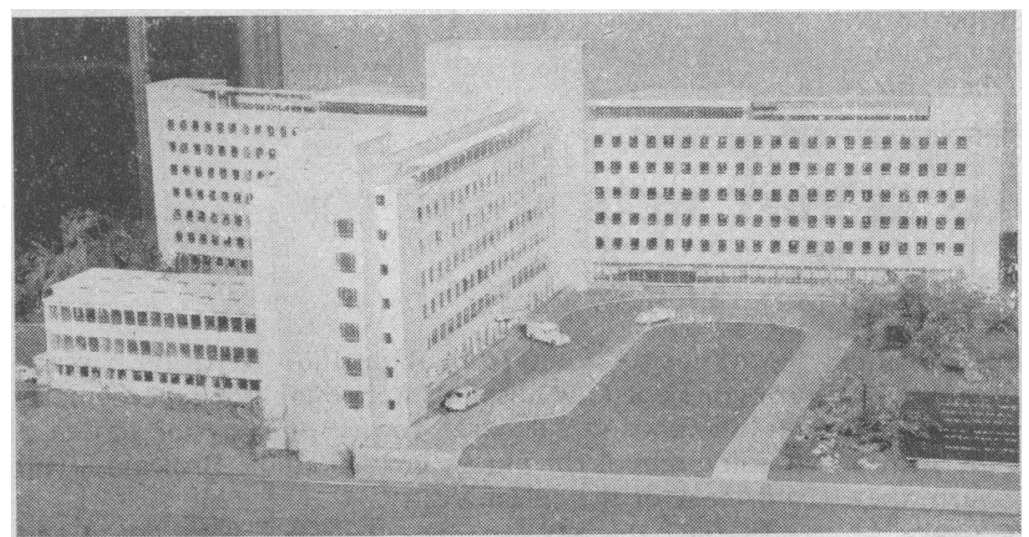

Fig. 8. -Welwyn Garden City and Hatfield Hospital, Hertfordshire. A simple conventional regional board hospital. Not too much glass. Costs : 330 general beds at $£ 5,900$ per bed; 100 psychiatric beds at $£ 2,900$ per bed. Compare this with the prices for other recent projects. (Architect: F. A. C. Maunder, F.R.I.B.A.) Crown copyright.

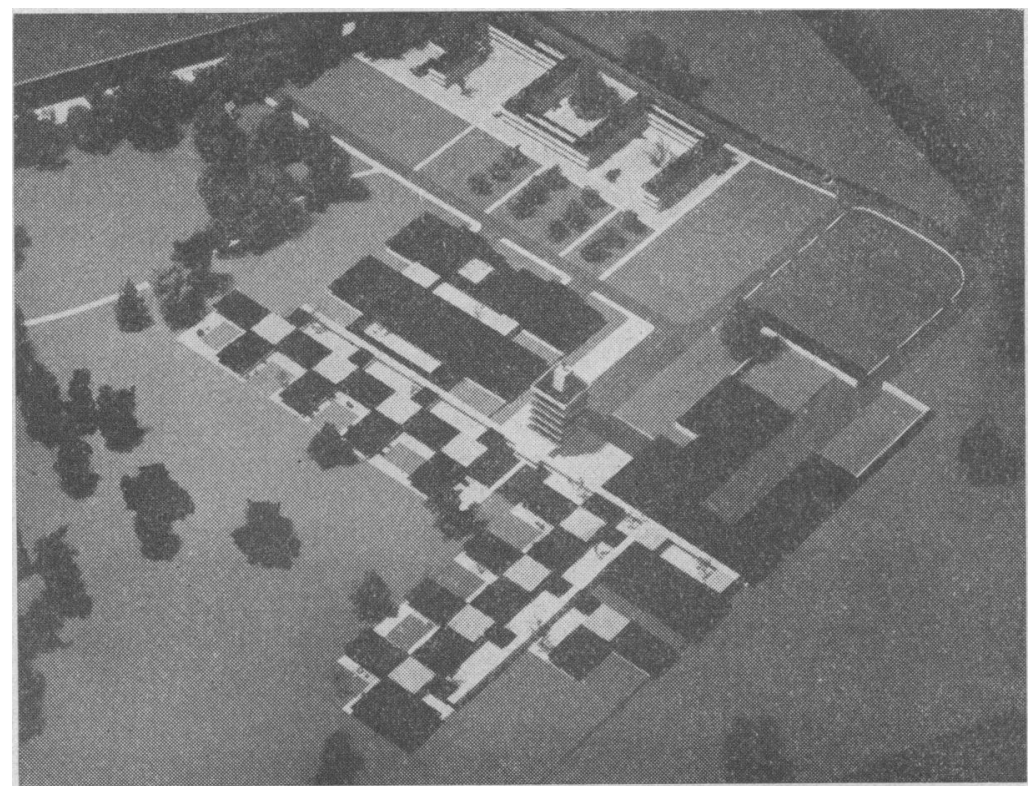

Fig. 9.-Wexham Park Hospital, Slough. Compact quadrangular single-story planning. The current estimated cost of stage 1 , which comprises 296 beds for planning. The current estimated cost of stage 1, which comprises 296 beds for (Architects: Powell and Moya, F.F.R.I.B.A. in association with R. Llewelyn Davies, F.R.I.B.A., and J. R. Weeks, A.R.I.B.A.) and the factory, there is no time for looking after patients properly in hospital. What the G.P. needs is open access to the pathology, $x$-ray, and physiotherapy partments; a good domiciliary consultant; homenursing, home-help, and health-visitor service at his dis is coming

At a certain point the hospital master-plan (or departmental plan in the case of reconstruction) has to turn into a brief for the architect. Here are some rules which be of value: of costs and extras which will arise during construction. Now deduct from your sum the cost of the site; cost of site works; cost of furnishing and equipment; architects', consulting engineers', and quantity surveyors' fees; and a margin for contingencies. What remains is what you can allow the architect to spend on the building. Remember the architect and his professional colleagues are paid on a percentage basis. So the more the buildings cost the greater are their profits. You can prevent overspending only if you brief the architect absolutely firmly right at the start, and watch him and yourself all the way through. If you or he make any variations, always ask for a written statement (to which you can hold him) of the extra cost involved. Architects are very nice people; you must be correspondingly tough.

2. Efficiency with Economy.-To obtain efficiency with $r$ e a s o n b le economy there has to be compromise all along the line, by users as well as by architects.

3. Keep all rooms as small as possible. - Specify room sizes whenever you can. The normal human units in medicine are two, three, or four people (including the doctor and patient). Keep your room heights low, domestic rather than institutional. The extra feet below the ceiling waste heat and make small rooms look depressing.

4. Beware of Too Much Glass (Figs. 7 and 8).-Ask yourself how every piece of glass can be cleaned from the outside. Forbid glass or curtain walls. Be careful of picture windows which will not open. Architects hold the mistaken belief, arising from the Rollier heliotherapy of the $1930 \mathrm{~s}$, that the sun has magical therapeutic properties. They forget that the sick need privacy rather than publicity, though a view from the bed is nice if you can get it. They forget that patients have to undress. They forget the misery of being over- heated and over-illuminated on a bright day if one is ill. Their usual answer is the aluminium vepetian blind. This filthy object is almost impossible to keep clean and free from dust and germs. It should be forbidden. 
5. Beware of new fancy materials and flat roofs.-After bitter experience, we have forbidden flat roofs in our new town. Even the best flat roofs expand and contract, so producing leaks at the points where they join the walls. Most architects want to use the latest building novelties, which have not stood the test of time. Refuse firmly to be their experimental animals. Brick and stone are still the two best building materials. What was good enough for Wren is good enough for you.

6. Pick your tender list of contractors very carefully. -Better still, negotiate a contract with a good firm of builders. Establish good relations with your site agent and foreman, but never issue an instruction direct to them. This is an "extra " for which you will be charged through the nose. Most builders are honest, good craftsman who want to give you a good job. If architect and builder disagree on a practical point, the builder will often be right.

7. If the site permits, have a tightly designed singlestory building, or at the most two stories (Fig. 9). If possible avoid monumental slabs or towers. They enforce rigidity on the unknown needs of the future. On limited town sites tall buildings may be inevitable. See where they cast their shade. Low buildings adjacent may never see the sun. For hostels or staff flats, how- ever, tall buildings have much to commend them. Good quadrangular building is, in my view, the ideal form, giving compactness, beauty, and flexibility on a human scale. Think of Oxford and Cambridge Colleges and do likewise if you can.

8. Put the patient in the centre of the picture first, last, and all the time.

9. Get from the Ministry of Health an overall sum within which you must work. Provided you keep within this sum, and your own master-plan, press forward regardless of man-made obstructions. You may get the sack-or a knighthood. Neither matters, for you will have served the community and the patients properly. That is the object of the exercise.

\section{REFERENCES}

1 Report of the Ministry of Health for 1959, Cmnd. 1086. H. M.O. London.

- Taylor, S., Good General Practice, 1954. Oxford Univ. Press, London.

Scott, E., J. Coll. gen. Practit., 1960, 3, 80.

Brit. med. J., 1958, 1, 884.

Davies, R. Llewellyn, et al., Studies in the Function and Design of Hospitals, 1955 [Nuffield Provincial Hospitals Trust]. Oxford Univ. Press, London.

- Barr, A., Lancet, 1957, 2, 1105.

Forsyth, G., and Logan, R. F. L., The Demand for Medical Care, 1960. Oxford Univ. Press, London.

- McKeown, T., Brit. med. J., 1959, 1, Suppl. p. 122.

\section{BRITISH HOSPITALS AS THEY WERE BEFORE 1948}

\section{BY}

\section{Sir ALLEN DALEY, M.D., LL.D., F.R.C.P.}

Though it is only twelve years since the National Health Service was introduced there are many now working in, or associated with, the hospital section of the Service who have little or no personal knowledge of the British hospitals as they were before July, 1948, when they were taken over by the State.

There have been places for the care of the sick from the dawn of civilization, and throughout the ages many men and women with an urge to help suffering mankind have been drawn to serve in them. It was an urge similar to that which drew them into religious communities.

Bishop Basil founded a hospital at Caesarea in A.D. 370 and Archbishop Chrysostom one at Constantinople in A.D. 400 . In Britain the first general hospital of which there is record, St. Peter's, York, was founded by the Saxon King Athelstan and the Cathedral Canons; St. John's, York, was started by Lanfranc, Archbishop of Canterbury, in 1084. The oldest British hospital still functioning is St. Bartholomew's, Rochester, which began in 1078 as a leper hospital. It was soon followed by St. Bartholomew's, London, founded in 1123 by Rahere, the monk. After the dissolution of the monasteries, Bart's, along with the other four " Royal Hospitals," was put by King Henry VIII under the care of the City Corporation.

\section{Care of the Sick Under the Poor Law}

Soon after this the great Poor Law Statute of Queen Elizabeth I was passed, and the State took over from the Church responsibility for the destitute, including the poor who were ill. The Poor Law was reformed in 1834 ; "Guardians" replaced the "Overseers" of the poor; larger administrative units were formed by the union of parishes ; " sick wards" were established in the "workhouses"; and from about 1867 "separate" infirmaries or Poor Law hospitals were established, particularly in London and the large towns. Liverpool started a training-school for nurses in 1865 at the Brownlow Hill Infirmary of the Select Vestry.

In 1867 the Metropolitan Poor Act was passed and the Metropolitan Asylums Board was formed to take certain classes of the sick-poor out of the workhouses. The Board's service was the first organized hospital system of this country. It provided and administered hospitals for those suffering from fevers, for the mentally defective, for children needing long-stay hospital care, and for the tuberculous.

The Local Government Act, 1929, abolished the Boards of Guardians and the Metropolitan Asylums Board and transferred their functions to the councils of counties and county boroughs. The final break-up of the Poor Law had to wait until 1948.

Voluntary Hospitals

Throughout this period prejudice against the way in which the Poor Law Acts were administered was growing, and voluntary hospitals were established in considerable numbers, particularly during the eighteenth century and the first half of the nineteenth. The springs of benevolence flowed freely to mitigate the hardships of the poor. Most of the hospitals established about this time were general hospitals, but the Society of Friends built a mental hospital in York at the close of the eighteenth century, and the London Fever Hospital was founded in 1802 .

\section{Local Authority Hospitals}

From about 1866 yet another type of hospital had been developing-namely, that organized by the local councils. It started with isolation or fever hospitals, 